\title{
COEXISTENCE OF PROSTATE NEOPLASIA IN PATIENTS UNDERGOING RADICAL CYSTOPROSTATECTOMY DUE TO VESICAL NEOPLASIA
}

\author{
FREDERICO R. ROMERO, MARÍLIA G. DE CASTRO, ADALBERTO ANDRIOLO JÚNIOR, \\ ALEX H. DE MENESES, RONI C. FERNANDES, MARJO D.C. PEREZ
}

Sections of Urology and Pathology, School of Medical Sciences, Santa Casa de São Paulo, São Paulo, Brazil

\begin{abstract}
Objective: To assess the incidence of bladder carcinoma infiltrating the prostate and prostate adenocarcinoma in patients undergoing radical cystoprostatectomy due to bladder cancer, as well as to assess if the characteristics of the bladder neoplasia influence the prostatic involvement by this neoplasia.

Materials and Methods: We retrospectively assessed 60 male patients, who underwent radical cystoprostatectomy between July 1997 and December 2003. Mean age was 66.7 years (40 and 93 years). The product of radical cystoprostatectomies was checked for involvement of urethra and prostate parenchyma by the primary neoplasia, and for the presence of associated prostate adenocarcinoma. Bladder neoplasia characteristics, such as localization, size, multifocality, association with in situ carcinoma and histological grade, were studied in order to assess the possibility of using such characteristics as predictive factors of prostate infiltration by bladder urothelial carcinoma.

Results: We observed the presence of $20 \%$ of patients with bladder carcinoma infiltrating the prostatic urethra, $23.3 \%$ of patients with infiltration of the prostate parenchyma and $28.3 \%$ of patients with associate prostate adenocarcinoma, resulting in a total of $55 \%$ of patients with prostatic involvement (infiltrative bladder carcinoma and/or adenocarcinoma). We also observed a statistically significant correlation between tumor location in the trigone, the presence of in situ carcinoma and the histological grade of the bladder tumor with prostatic infiltration by the vesical neoplasia.

Conclusion: The coexistence of prostatic neoplasia in patients operated for bladder neoplasia was frequent in our sample (55\%). We observed that the prostatic infiltration by bladder tumors occurs more frequently with tumors located in the trigone, with associated in situ carcinoma and with high histological grade. There was no correlation between neoplastic infiltration of prostate and multifocality or size of the bladder tumor in the studied sample.
\end{abstract}

Key words: bladder neoplasms; neoplasm invasiveness; prostatic neoplasms; cystectomy Int Braz J Urol. 2004; 30: 296-301

\section{INTRODUCTION}

Radical cystoprostatectomy with urinary reconstruction represents the most efficient treatment for invasive or refractory bladder cancer, with cure indexes up to $80 \%$ of treated cases (1). However, due to the high incidence of complication with this procedure, alternative techniques have been recently described, preserving the prostate apex, or even the prostate capsule, aiming to preserve sexual and urinary functions of operated patients (1-3).

Due to the increasing number of patients undergoing procedures with urethral preservation, more attention has been given to prostatic invasion by bladder neoplasia, which certainly increases the risk of urethral recurrence and death from the neoplasia (4), 
particularly in those patients with invasion of the prostate parenchyma (5).

Additionally, several studies have shown the high incidence of incidental prostate adenocarcinoma in specimens from cystoprostatectomies performed for treating bladder cancer $(3,6-9)$. Some of them reported a predominance of tumors in the prostate apex $(3,6)$. Patients with bladder neoplasia can present prostate neoplasia with a relative risk up to 19 times higher than what would be expected (10). However, incidental prostate tumors present characteristics that are similar to latent tumors found in autopsy series, some have a proven potential of progressive disease (3).

The objective of this work is to verify the incidence of tumoral infiltration (urethra and/or parenchyma) in the prostate of patients who underwent radical cystoprostatectomy for bladder urothelial carcinoma, as well as the presence and histological grade of the incidental prostate adenocarcinoma. The characteristics of bladder tumors invasive to urethra or prostate parenchyma were also assessed, in separate groups, with the objective of predicting those patients with higher predisposition to associated prostatic disease.

\section{MATERIALS AND METHODS}

We conducted a retrospective study of all patients undergoing radical cystoprostatectomy for management of bladder urothelial (or transitional cell) carcinoma during the period from July 1997 to December 2003. The inclusion criteria comprised male patients, who underwent radical cystoprostatectomy for management of bladder urothelial carcinoma, whose surgical specimens were histologically examined.

Female patients were excluded, as well as patients undergoing partial cystectomy, patients with different histological diagnosis other than bladder urothelial carcinoma and/or patients with irresectable tumors. Among a total of 84 patients who underwent open surgery for management of bladder carcinoma between 1997 and 2003, 60 fulfilled the inclusion criteria. Mean age of patients was 66.5 years, with age limits ranging between 40 and 93 years. All patients underwent radical cystoprostatectomy.

Staging and histological grading, according to the TNM system of the International Union Against Cancer (UICC) and grading system of the World Health Organization (WHO), respectively, are illustrated in Table-1. In relation to urinary reconstruction, $48(80 \%)$ patients underwent ileal conduct, 11 $(18.3 \%)$ orthotopic neobladder, 2 (3.3\%) ureterosigmoidostomy and $2(3.3 \%)$ wet colostomy.

The product from the radical cystoprostatectomies was fixed in 10\% formalin solution and processed according to the usual standards for fixation and inclusion routinely employed in pathology services.

The specimens were weighted and measured. The majority of specimens were opened through the anterior bladder wall. In average, 2 to 5 sections were made to each tumor (depending on the size), in addition to random sections in the following bladder regions: dome, right and left lateral walls, posterior e anterior walls, triangle and urethral margin of the bladder.

The prostate was sectioned in quadrants, similarly o the processing for radical prostatectomy specimens. Sections from transitional and peripheral zones of the prostate, and from apical, middle and basal regions in both lobes were included, resulting, in average, in 6 blocks per case. The margin of prostatic urethra was represented separately. The blocks were sectioned in slices with 3- to 5-micrometers in thickness and the resultant histological slides were stained by hematoxylin-eosin.

Table 1 - Staging and histological grade of bladder tumors.

\begin{tabular}{lccrrrr}
\hline & Ta & T1 & T2 & T3 & T4 & Total \\
\hline Low grade & 3 & 5 & 3 & 4 & 1 & 16 \\
High grade & 0 & 1 & 11 & 14 & 18 & 44 \\
Total & 3 & 6 & 14 & 18 & 19 & 60 \\
\hline
\end{tabular}


In relation to the characteristics of bladder neoplasias, the variables included in the analysis were tumoral location in bladder, assessing invasion, or not, of the vesical triangle, tumoral multifocality, presence or absence associated in situ carcinoma in the adjacent vesical mucosa, and histological grade, according to the classification system of the WHO (11).

The correlation between these characteristics and the incidence of neoplastic infiltration of bladder carcinoma to prostate were assessed by Fisher's exact test.

\section{RESULTS}

Of the 60 who underwent radical cystoprostatectomy for bladder neoplasia, we observed that 18 (30\%) patients presented urethral (20\%) and/or parenchymal (23.3\%) invasion of the prostate. Due to the extremely distinct prognostic connotations between the infiltration of urethra and prostate parenchyma, since parenchymal invasion results in poorer survival (5), we separated the groups and assessed the characteristics of bladder tumors with these different forms of invasion. Among the total of assessed patients, $36(60 \%)$ presented tumor in the trigone, including $9(25 \%)$ with infiltration of the prostatic urethra and $12(33.3 \%)$ with infiltration of prostatic parenchyma by the bladder urothelial carcinoma.

On the other hand, 3 (12.5\%), of the 24 patients with tumors sparing the trigone, presented urethral infiltration, while only $2(8.3 \%)$ of them presented parenchymal infiltration. This result did not show statistically significant differences in relation to invasion of the prostatic urethra, but was significant in relation to infiltration of the prostatic parenchyma (Table-2). Similar results were observed when the presence of in situ carcinoma was observed in the adjacent mucosa vesical.

Of the $18(30 \%)$ patients with in situ carcinoma in vesical mucosa, $8(44.4 \%)$ presented invasion of prostatic urethra and 7 (38.9\%) presented infiltration of prostatic parenchyma, while only $4(9.5 \%)$ of 42 patients without associated in situ carcinoma showed prostatic urethral involvement and, 7 (16.6\%), prostatic parenchymal involvement (Table-3). Additionally, patients with high-grade bladder carcinoma also presented higher incidence of prostatic infiltration, both urethral and parenchymal, when compared with those with low-grade tumor. Of the 44 (73.3\%)

Table 2 - Correlation between the presence of prostate infiltration and the location of the bladder neoplasia in the trigone.

\begin{tabular}{lccc}
\hline $\begin{array}{l}\text { Prostate } \\
\text { Infiltration }\end{array}$ & Present - N (\%) & $\begin{array}{c}\text { Tumor in Trigone } \\
\text { Absent - N }(\%)\end{array}$ & p Value \\
\hline Urethra & $9(25)$ & $3(12.5)$ & 0.197 \\
Parenchyma & $12(33.3)$ & $2(8.3)$ & 0.023 \\
Absent & $22(61.1)$ & $20(83.3)$ & 0.058 \\
Total & $36(60)$ & $24(40)$ & \\
\hline
\end{tabular}

Table 3 - Correlation between the presence of prostate infiltration and the presence of in situ carcinoma in the adjacent vesical тисова.

\begin{tabular}{lccc}
\hline $\begin{array}{l}\text { Prostate } \\
\text { Infiltration }\end{array}$ & Present - N (\%) & $\begin{array}{c}\text { In Situ Bladder Carcinoma } \\
\text { Absent - N (\%) }\end{array}$ & p Value \\
\hline Urethra & $8(44.4)$ & $4(9.5)$ & 0.004 \\
Parenchyma & $7(38.9)$ & $7(16.6)$ & 0.065 \\
Absent & $8(44.4)$ & $34(81)$ & 0.005 \\
Total & $18(30)$ & $42(70)$ & \\
\hline
\end{tabular}


patients with high-grade tumors, $12(27.3 \%)$ presented infiltration of prostatic urethra and $14(31.8 \%)$ infiltration of parenchyma, while none of the 16 patients with low-grade tumor, presented this particularity (Table-4). Prostatic involvement was evaluated in patients with multifocal bladder tumors as well (Table-5), but there was no statistically significant difference in this sample. Similarly, the association between size of the vesical tumor (smaller, equal or larger than $3 \mathrm{~cm}$ ) and the presence of prostatic infiltration was not statistically significant, as shown in Table-6.

Prostate adenocarcinoma was an incidental finding in $17(28.3 \%)$ patients. Of these, $16(94.1 \%)$ had a combined Gleason score lower or equal to 6 and only $1(5.9 \%)$ presented Gleason score equal to 7 $(3+4)$.

When grouping all patients with infiltrative urothelial carcinoma in prostate and/or primary prostate adenocarcinoma, $33(55 \%)$ presented coexisting prostatic neoplasia.

\section{COMMENTS}

It was determined that 20 to $40 \%$ of patients undergoing radical cystoprostatectomy due to bladder urothelial carcinoma can present infiltration of urethra and/or prostatic parenchyma by the bladder neoplasia $(4,12)$. In our series, $30 \%$ of patients were diagnosed with tumoral invasion of prostate, and this

Table 4 - Correlation between the presence of prostate infiltration and histological grade of the bladder urothelial carcinoma.

\begin{tabular}{lccc}
\hline $\begin{array}{l}\text { Prostate } \\
\text { Infiltration }\end{array}$ & High grade - N $(\%)$ & $\begin{array}{r}\text { Histological Grade } \\
\text { Low grade - N }(\%)\end{array}$ & p Value \\
\hline Urethra & $12(27.3)$ & $0 \quad(0)$ & 0.015 \\
Parenchyma & $14(31.8)$ & $0 \quad(0)$ & 0.007 \\
Absent & $26(59.1)$ & $16(100)$ & 0.001 \\
Total & $44(73.3)$ & $16(26.7)$ & \\
\hline
\end{tabular}

Table 5 - Correlation between the presence of prostate infiltration and tumor multifocality.

\begin{tabular}{lccc}
\hline $\begin{array}{l}\text { Prostate } \\
\text { Infiltration }\end{array}$ & Present - N (\%) & $\begin{array}{c}\text { Multifocality } \\
\text { Absent - N (\%) }\end{array}$ & p Value \\
\hline Urethra & $5(19.2)$ & $7(20.6)$ & 0.58 \\
Parenchyma & $5(19.2)$ & $9(26.5)$ & 0.36 \\
Absent & $19(73.1)$ & $23(67.6)$ & 0.43 \\
Total & $26(43.3)$ & $34(56.7)$ & \\
\hline
\end{tabular}

Table 6 - Correlation between the presence of prostate infiltration and size of bladder urothelial carcinoma.

\begin{tabular}{lccc}
\hline $\begin{array}{l}\text { Prostate } \\
\text { Infiltration }\end{array}$ & $>3 \mathrm{~cm}-\mathrm{N}(\%)$ & $\begin{array}{c}\text { Size } \\
\leq 3 \mathrm{~cm}-\mathrm{N}(\%)\end{array}$ & $\mathrm{p}$ Value \\
\hline Urethra & $8(18)$ & $4(25)$ & 0.82 \\
Parenchyma & $11(25)$ & $3(18.7)$ & 0.44 \\
Absent & $31(70.4)$ & $11(68.7)$ & 0.67 \\
Total & $44(73.3)$ & $16(26.7)$ & \\
\hline
\end{tabular}


incidence reached $55.5 \%$, in patients with associate in situ carcinoma.

Additionally, we found an increase in the incidence of prostatic infiltration in patients with tumors located in the vesical triangle and in those with high-grade urothelial neoplasias, with incidences of $41.6 \%$ and $41 \%$, respectively. The high risk of prostatic involvement by bladder tumors located close to the bladder neck, multifocal or associated with in situ carcinoma has been previously reported $(5,13)$. The assessment of such factors is important because it can help when deciding whether to partially preserve or to completely resect the prostate, when treating patients with infiltrative bladder neoplasia.

Recent reports indicate that the invasion by urothelial carcinoma to the prostatic urethra does not alter survival, contrarily to parenchymal invasion of the prostate (5).

However, the infiltration of prostatic urethra can be associated with higher risk of urethral recurrence. In the present study, we observed a statistically significant correlation between urethral infiltration of the prostate and the presence of in situ carcinoma of vesical mucosa as well as a high histological grade. On the other hand, the incidence of infiltration of the prostatic parenchyma was significantly higher in patients with tumor located in the trigone and in those with high-grade urothelial neoplasia.

The diagnosis of incidental prostate adenocarcinoma in these patients was reported in $16 \%$ to $46 \%$ in cases, in the reviewed works $(3,6-9)$. In our patients, $28.3 \%$ of operated patients presented prostatic adenocarcinoma.

Though the discrepancies between studies could be related to the method of pathologic evaluation employed, all indicate the presence of a significantly high incidence of associated disease (3). Several authors observed a relative risk of patients with bladder cancer developing prostate cancer that is 9 to 19 times higher than the expected rate $(3,4)$. These incidental tumors are usually small, well or moderately differentiated and limited to the prostate. Almost all our patients $(94.1 \%)$ presented combined Gleason score lower or equal to 6 .

Only one patient $(5.9 \%)$ presented Gleason $7(3+4)$. These studies represent the closest correla- tion as possible between living patients and autopsy series that study incidental or latent prostate adenocarcinoma. However, in the modern age of orthotopic bladder replacement, where some authors have proposed preservation of prostatic tissue or prostatic capsule, the precise location, histological grade and size of these tumors are important factors to be considered. Several studies observed a high frequency of prostate tumors close or located in the prostate apex, so that an incomplete radical surgery of prostate could impair the principles of oncologic surgery $(3,6)$. In our sample, it was impossible to determine the precise location of tumors due to the relatively recent standardization of surgical specimens processing.

When assessed together, invasive urothelial carcinoma in prostate and adenocarcinoma can be found in 40 to $80 \%$ of patients (2). In the present work, we found prostatic involvement in 55\% of patients, by prostatic invasion either by the bladder tumor (30\%), or by the presence of an associated prostate adenocarcinoma $(28.3 \%)$.

Thus, in addition to a proper patient selection in order to rule out prostate adenocarcinoma in patients who are candidates to surgery with preservation of the prostate apex, through clinical examination, serum levels of prostate specific antigen, transrectal ultrasound and prostate biopsy, a detailed assessment of the bladder neoplasia's characteristics must be performed, with urethrocystoscopy, endoscopic resection and randomized biopsy of bladder. In this way, the possibility of missing a diagnosis of coexisting prostate neoplasia is reduced (3,6-9). Additionally, it is possible to perform an intra-operative freezing biopsy of the urethral margin in order to further reduce this possibility $(13,14)$.

Though several works have concluded that the resection of the prostate apex is mandatory during cystoprostatectomy for bladder cancer $(3,6,9)$, the preservation of the prostate apex can reduce the morbidity and significantly improve the patients' quality of life through improving social, sexual and psychological implications of the radical cystectomy (1). The proper selection of patients through a detailed preoperative evaluation can allow this procedure to be performed, but prospective studies will be required 
to follow these patients' outcome in order to assess if the preservation of prostate apex really impairs survival and the risk of urethral recurrence in these patients.

\section{CONCLUSION}

The presence of prostatic involvement by local infiltration of bladder neoplasia and/or synchronous prostate adenocarcinoma was frequent in our sample $(55 \%)$. We observed that the infiltration of prostatic urethra by bladder urothelial tumors occurs more frequently in tumors with in situ carcinoma in the adjacent vesical mucosa and in those with high histological grade. The parenchymal infiltration of prostate by urothelial carcinoma was more common among tumors located in the trigone and in high-grade tumors as well. We found no association between multifocality and size of bladder tumor with the presence of urothelial carcinoma in the prostate.

\section{REFERENCES}

1. Spitz A, Stein JP, Lieskovasky G, Skinner DG: Orthotopic urinary diversion with preservation of erectile and ejaculatory function in man requiring radical cystectomy for nonurothelian malignancy: a new technique. J Urol. 1999; 161: 1761-64.

2. Srougi M, Dall'Oglio M, Nesrallah LJ, Arruda HO: Radical cystectomy with preservation of sexual function and urinary continence: description of a new technique. Int Braz J Urol. 2003; 29: 336-44.

3. Moutzouris G, Barbatis C, Plastiras D, Mertziotis N, Katsifotis C, Presvelos V, et al.: Incidence and histological findings of unsuspected prostatic adenocarcinoma in radical cystoprostatectomy for transitional cell carcinoma of the bladder. Scand J Urol Nephrol. 1999; 33: 27-30.

4. Iselin CE, Robertson CN, Webster GD, Vieweg J, Paulson DF: Does prostate transitional cell carcinoma preclude orthotopic bladder reconstruction after radical cystoprostatectomy for bladder cancer?. J Urol. 1997; 158: 2123-6.

5. Nixon RG, Chang SS, Lafleur BJ, Smith Jr JA, Cookson MS: Carcinoma in situ and tumor multifocality predict the risk of prostatic urethral involvement at radical cystectomy in men with transitional cell carcinoma of the bladder. J Urol. 2002; 167 (2 pt1): 502-5.
6. Kabalin JN, McNeal JE, Price HM, Freiha FS, Stamey TA: Unsuspected adenocarcinoma of the prostate in patients undergoing cystoprostatectomy for other causes: incidence, histology and morphometric observations. J Urol. 1989; 141: 1091-4.

7. Pritchett TR, Moreno J, Warner NE, Lieskovsky G, Nichols PW, Cook BA, et al.: Unsuspected prostatic adenocarcinoma in patients who have undergone radical cystoprostatectomy for transitional cell carcinoma of the bladder. J Urol. 1988; 139: 1214-6.

8. Montie JE, Wood Jr DP, Pontes JE, Boyett JM, Levin HS: Adenocarcinoma of the prostate in cystoprostatectomy specimens removed for bladder cancer. Cancer.1989; 63: 381-5.

9. Winfield HN, Reddy PK, Lange PH: Coexisting adenocarcinoma of prostate in patients undergoing cystoprostatectomy for bladder cancer. Urology 1987; 30: 100-1.

10. Chun TY: Coincidence of bladder and prostate cancer. J Urol. 1997; 157:65-7.

11. Eble JN, Sauter G, Epstein JI, Sesterhenn IA: IARC World Health Organization classification of tumours: pathology and genetics of tumours of the urinary system and male genital organs. Lyon, 2004.

12. Wood Jr DP, Montie JE, Pontes JE, VanderBrug Medendorp S, Levin HS: Transitional cell carcinoma of the prostate in cystoprostatectomy specimens removed for bladder cancer. J Urol. 1989; 141: 346-9.

13. Nabeeh A, Gomha M, Shaaban AA, el-Baz M, elDosoky I, Ashamallah A, et al.: Orthotopic bladder substitutes: histopathologic risk factors. Scand J Urol Nephrol. 1995; 29: 463-7.

14. Vallancien G, el Fettouh HÁ, Cathelineau X, Baumert H, Fromont G, Guillonneau B: Cystectomy with prostate sparing for bladder cancer in 100 patients: 10-year experience. J Urol. 2002; 168: 2413-7.

Received: May 4, 2004

Accepted after revision: July 29, 2004 